\title{
Merkel cell carcinoma: literature review
}

\author{
Abdalla Saad Abdalla Al-Zawi ${ }^{1}$, Andrew Prodromou ${ }^{1}$, \\ Wayne Chicken ${ }^{1}$, Turhan Comez ${ }^{1}$, Ekin Deniz ${ }^{2}$
}

Merkel cell carcinoma (MCC) was given a such name after the German histopathologist Friedrich Merkel, who first in 1875 , described the Merkel cells, as small round or oval basophilic cells located at the end of nerve axons and within the basal layer of the epidermis. The current agreement about the function of Merkel cells they are associated with the nerve terminals acting as mechanoreceptors. MCC is a clinically aggressive uncommon, cutaneous neuroendocrine neoplastic tumour with a high mortality rate. Clinically may be presented as a painless, rapidly growing, dome-shaped red or purplish nodule. Usually in a sun-exposed area of the head and neck or upper limbs. Tremendous effort has been done in the last few years for a better understanding of the pathogenesis behind the MCC and the discovery of the Merkel cell polyomavirus suggests another clue to its pathogenesis. The expression of both epithelial and neuroendocrine immunohistochemical markers in the malignant cells, gives the tumour a unique feature that helps differentiate this neoplasm from other entities.

NOWOTWORY J Oncol 2017; 67, 2: 127-131

Key words: Merkel cell carcinoma, trabecular carcinoma, Toker tumour, polyomavirus

\section{Introduction}

Merkel cell carcinoma (MCC) is a highly aggressive neuroendocrine carcinoma of the skin. In spite it is a rare tumour, its incidence is increasing. It is known to have high rates of recurrence and distant metastasis. MCC is a frequently lethal skin cancer with a higher mortality (33\%) than melanoma (15\%) [1]. This cancer is known with rapid progression course and poor prognosis. British National Cancer Intelligence Network 10 year incidence rate for rare skin cancer across English Cancer Registries (1999-2008) Report revealed evidence for increasing standardised incidence rates of Merkel cell carcinoma ( 0.1 to 0.2 per 100,000 population). Risk factors include, polyomavirus, UV light, immunosuppression and presence of other cancers as lymphomas.

\section{Historical background}

Freidrich Sigmund Merkel, a German histopathologist, first described the Merkel cells in 1875 using animal modules. They are clear-staining cells at the dermo-epi- dermal junction were near myelinated nerve fibers, they acted as mechanoreceptors, other Merkel cells that have no contact with nerve terminals appear to have an endocrine function [2]. Intriguingly, three years later, the term Merkel cell was born by a young anatomist Robert Bonnet who later worked with Dr. Merkel [3]. The first human cases was first reported in 1972 by Toker, who was born in South Africa and worked as a Professor of Pathology at University of Maryland School of Medicine in Baltimore, USA. He used the term "trabecular carcinoma" of the skin to describe a poorly differentiated carcinoma of the dermis and subcutaneous tissue $[4,5]$, this is why some papers called this disease as Toker Tumour.

\section{Epidemiology, risk factors \& pathogenesis}

MCC is a frequently lethal skin cancer with a higher mortality (33\%) than melanoma (15\%) [1]. This cancer is known with rapid progression course and poor prognosis. British National Cancer Intelligence Network 10 year incidence

\footnotetext{
${ }^{1}$ Basildon University Hospital, England

${ }^{2}$ Faculty of Medicine, Istanbul Bilim University, Turkey
} 
rate for rare skin cancer across English Cancer Registries (1999-2008) Report revealed evidence for increasing standardised incidence rates of Merkel cell carcinoma (0.1 to 0.2 per 100,000 population). Risk factors include, polyomavirus, UV light, immunosuppression and presence of other cancers as lymphomas.

The increased incidence of the disease could be due to actual incidence increase. Other factors are blamed as growing aged population, increased sun exposure (Tropical Holiday Factor), tanning salons, advancement in immunohistochemical diagnostic techniques together with better registration facilities. MCC occurs more often among elderly fare skin patients with somewhat more commonly in males [6]. Mostcommonon sun-exposed areas or artificial light $[4,10,11]$. Predominantly occurred in head and neck area (more than $50 \%$ ) followed by limbs (40\%). The rest $10 \%$ reported in the trunk [4]. Non-sun exposed area MCC also has been reported as vulva [12], tongue [13] and gluteal area [14]. In the year 2008, a team from University of Pittsburgh, USA, came with new break through related to the pathogenesis of MCC. It is related to Merkel cell polyomavirus (MCV or MCPyV), reports mentioned that it is present in $80 \%$ of cases. It is a small novel polyomavirus with a genome consisting of double-stranded DNA. Thus, MCV may be a contributing factor in the pathogenesis of MCC $[6,15,16]$. The MCPyV large T antigen contains MCC tumor-specific mutations that withdraw its replication capability, however perpetuate its oncogenic functions, and the small $t$ antigen encourages an environment propitious for carcinogenesis [17, 18]. Immuno-suppression increases the relative risk of MCC especially with HIV, solid-organ transplant patients as well as autoimmune diseases [19-22]. Also patients with lymphoproliferative disorders as chronic lymphocytic leukaemia (CLL) have an increased risk of MCC [23].Other cancers associated with MCC are skin squamous cell carcinoma, basal cell carcinoma, malignant melanoma, Hodgkin lymphoma, Non-Hodgkin Lymphoma [24].

There are reports about primary MCC arises in the breast skin [25], however there is a case of coexistence of MCC with a breast cancer [26]. The reported observations support the existence of shared risk factors for MCC and other cancers. It is reported that the Merkel cell polyomavirus has a potential oncogenic effect $[1,15,16]$, is it possible that, this virus also related to the other cancers. This is a need for more research to be done in this field.

\section{Clinical picture}

Clinical picture could be a reddish blue, firm, non-tender, nodular mass that has grown rapidly over a few weeks or even for months, this may ulcerate. They metastasise to lymph nodes (55\%), liver, lung and bones (34-49\%) with a local recurrence rate of $40-44 \%$ after primary treatment. Rarer sites of metastasis has been described in testis [27], mesentery [28] and tibia [29]. Secondary disease is an indicative feature for poor prognosis.

American Joint Committee on Cancer (AJCC) and the International Union for Cancer Control (UICC) in the year 2010 recommended MCC TNM Staging System. This was based on retrospective study included 5823 from the National Cancer Database registry [30], see Table I.

\section{Histology}

The microscopic features may show Merkel cells with scanty cytoplasm, a small dark polygonal nucleus with granular chromatin and a high mitotic rate [29]. Generally speaking, the histological features of MCC are similar to those of various other tumours, such as metastatic small cell lung carcinoma, blastic haematological malignancies of skin/soft tissue, and melanoma. Usually presented as composed of strands or nests of uniform, small round cells with scanty cytoplasm, round to oval nucleus with powdery dispersed chromatin, and inconspicuous nucleoli [32], see Figures 1 and 2.

\section{Immunohistochemistry}

A distinctive histochemical feature of MCC, is the expression of both neuroendocrine and epithelial markers. It is positive for CK-20, which is a sensitive marker for MCC and present in $90-100 \%$ of cases. As CK-20 is positive in some cases of extra-pulmonary small cell lung carcinoma (SCLC) it is essential that, the immunological study should include TTF-1 (Thyroid Transcription Factor-1), which expressed in $80-100 \%$ of SCLC but negative in MCC $[33,34]$. CD56 is a sensitive marker for MCC but not specific [35]. Other immunohistochemical studies are need to confirm the diagnosis as the markers may coincide. One of those markers is CK-7(Cytokeratin-7) may be positive in carcinoid and basal cell carcinoma but negative in MCC. S- 100 protein is another marker used to differentiate between malignant melanoma (usually positive) and MCC (usually negative) [36]. Synaptophysin is a trans-membrane channel protein of small pre-synaptic vesicles. MCC consistently shows positive immunoreactions to synaptophysin [37]. A combined features of cutaneous squamous cell carcinoma (SCC) and MCC noticed in some cases. As the MCC component often exists within the dermis, and not in the epidermis, dermis including biopsies should be carried out when evaluating potential NMSC (Non- Melanomatous Skin Cancer). This enables, not to miss an unrevealed deadly neuroendocrine element with a too superficial shave, causing delays in diagnosis and management of this aggressive and often fatal tumor [38]. Quantitative polymerase chain reaction (PCR) assay we used to detect MCPyV (Merkel Cell polyomavirus) DNA, this was found to be positive in $80 \%$ of cases $[6,16]$. Most of the recurrence appears within the first six to 12 months after the initial diagnosis [25]. Initial management 
Table I. Summary of the 2010 American Joint Committee on Cancer Merkel Cell Carcinoma staging system by SB Edge 2010

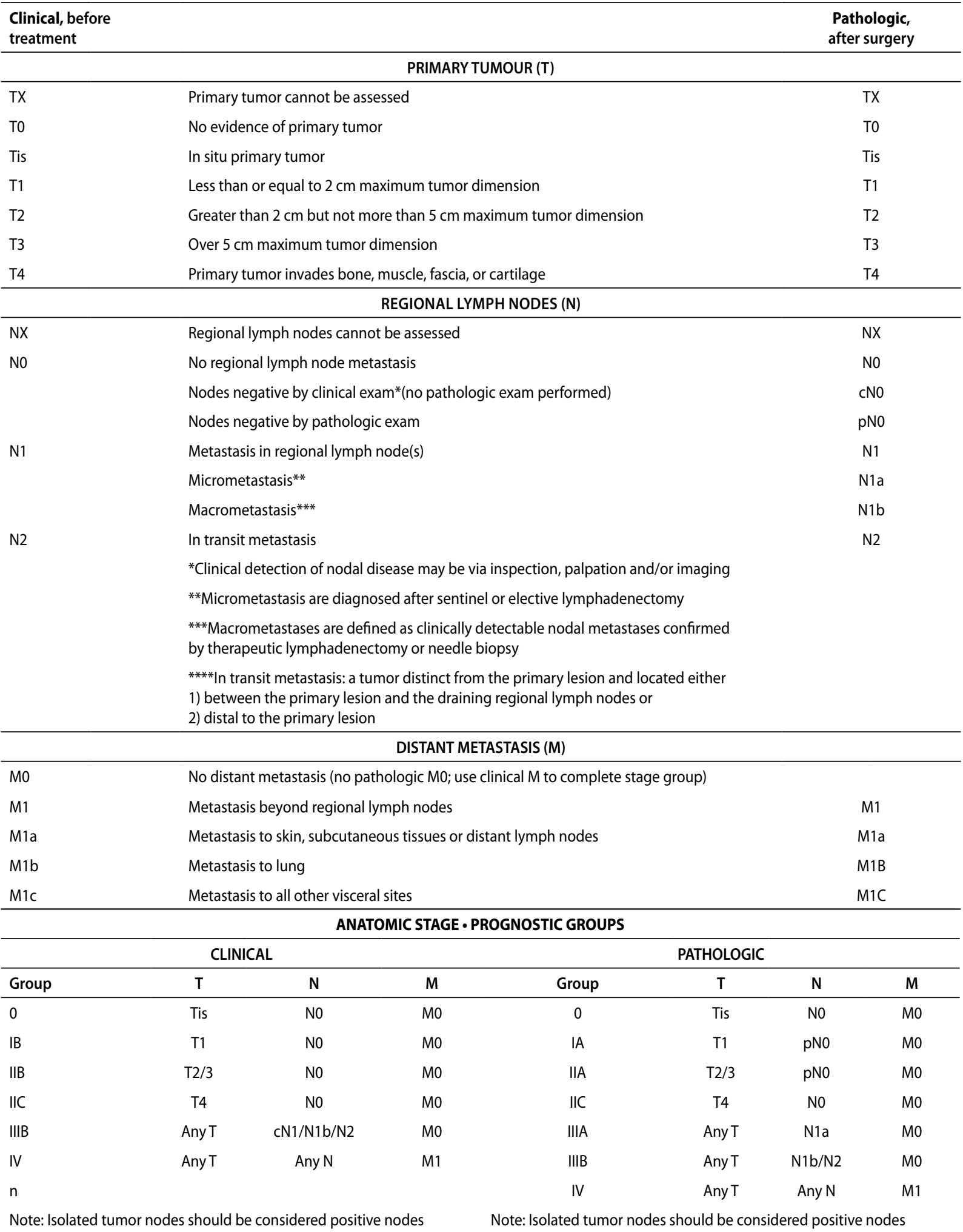




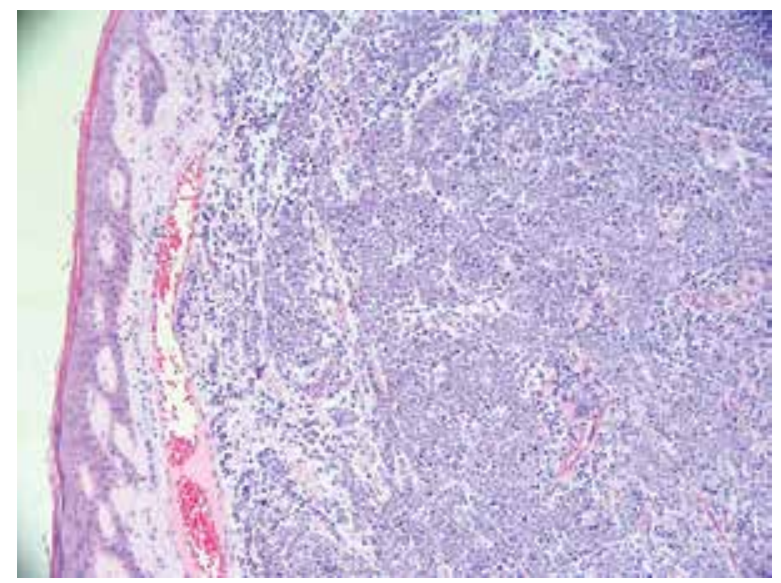

Figure 1. Merkel cell carcinoma - the tumour invades the dermis and subcutaneous tissue $(10 \times$ magnification)

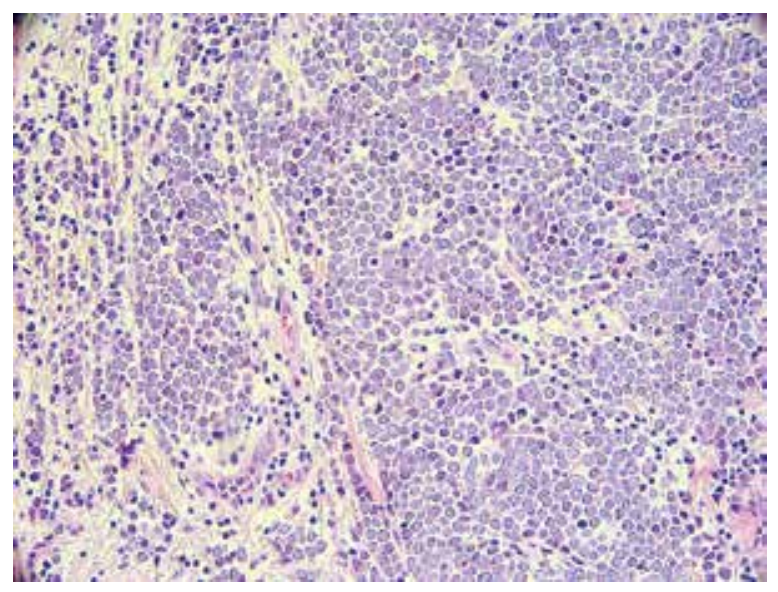

Figure 2. Poorly differentiated neoplasm, composed of medium-sized cells with dark nuclei and indistinct cytoplasm. There is apoptosis and brisk mitosis ( $20 \times$ magnification)

of the patients has a significant impact on disease progression. This depends on the time of the first presentation and initiating the targeted treatment, this factor is decisive to disease prognosis. Immuno-histochemistry staining for cytokeratin 20 needed for diagnosis.

\section{Treatment}

Current optimal treatment is with radical surgical excision of the primary tumour, sentinel lymph node biopsy, \pm regional lymph node dissection, radiotherapy, chemotherapy \& immunotherapy $[10,39,40]$.

Advanced Merkel-cell carcinoma often responds to chemotherapy, but responses are transient. Interfering with the programmed death 1 (PD-1) immune inhibitory pathway is of interest, because MCC often express PDL1, and MCPyV-specific T cells express PD-1. Using Pembrolizumab to block PD-1 revealed objective response rate of $56 \%$. Responses were observed in patients with virus-positive tumours and those with virus-negative tumours [41]. MCC response to Nivolumab immunotherapy in the current clinical trials is promising [42].

\section{Future}

A trial of Pazopanib for Merkel cell skin cancer (UKM-CC-01). Phase 2 Recruitment started:01/12/2012 and ended: $09 / 02 / 2016$, currently awaiting results.

\section{Conclusion}

MCC is an aggressive cutaneous malignancy. The incidence of MCC is on the rise, and steadily ascend awareness along with moving forward in immuno-histochemistry staining techniques have greatly facilitated the diagnosis. The published reports heightened awareness of the association between MCC and other cancers. Further research is needed to explore this issue. Also there is a need to implement evidence-based management guidelines for MCC patients, especially that the inadequate initial management of many patients may contribute to the unfavourable disease progression and prognosis.

\section{Conflict of interest: none declared}

\section{Dr Abdalla Saad Abdalla Al-Zawi}

M.B.B.Ch, SD in Surgery, PhD Consultant Breast Surgeon Basildon University Hospital, England

e-mail:abdalasaad@gmail.com

Received: 14 Jan 2017

Accepted: 23 Mar 2017

\section{References}

1. Lemos B, Nghiem P. Merkel cell carcinoma: more deaths but still no pathway to blame. J Invest Dermatol 2007; 127: 2100-2103.

2. Halata Z, Grim M, Bauman KI. Friedrich Sigmund Merkel and his "Merkel Cell", morphology, development, and physiology: review and new results. Anat Rec A Discov Mol Evol Biol 2003; 271: 225-239.

3. Erovic I, Erovic BM. Merkel cell carcinoma: the past, the present, and the future. J Skin Cancer 2013; 2013: 92936.

4. Popp G. Kerkel cell carcinoma of the skin. Hospital Physician 2009: 1-6.

5. Troker C. Trabecular carcinoma of the skin. Arch Dermatol 1972; 105: 107-110.

6. Sihto $\mathrm{H}, \mathrm{Kukko} \mathrm{H}$, Koljonen $\mathrm{V}$ et al. Clinical factors associated with Merkel cell polyomavirus infection in Merkel cell carcinoma. J Nat/ Cancer Inst 2009; 101: 938-945.

7. Saini AT, Miles BA. Merkel cell carcinoma of the head and neck: pathogenesis, current and emerging treatment options. OncoTargets Ther 2015; 8: 2157-2167.

8. Lebbe C, Becker JC, Grob JJ et al. Diagniosis and treatment of Merkel cell carcinoma. European consensus-based interdisciplinary guideline. Eur J Cancer 2015; 51: 2396-2403.

9. Nghiem P, McKee PH, Haynes HA et al (eds). American Cancer Society. Atlas of clinical oncology: skin cancer: Merkel cell. Hamilton, London: BC Decker Inc, 2001.

10. Carneiro C, Spalchiero J, Grazios G et al. Clinical presentation, prognostic factors, treatment and survival in 32 patients. Rev Bras Cir Plást 2013; 28: $196-200$.

11. Pfizer, Merck KgaA. Fact sheet. Merkel cell carcinoma. May 2016. www. pizer.com.

12. Nguyen AH, Tahseen Al, Vaudreuil AM et al. Clinical features and treatment of vulvar Merkel cell carcinoma: a systematic review. Gynecol Oncol Res Pract 2017; 4: 2. 
13. Yom SS, Rosenthal DI, El-Naggar AK et al. Merkel cell carcinoma of the tongue and head and neck oral mucosal sites. Oral Surg Oral Med Oral Pathol Oral Radiol Endod 2006; 101: 761-768.

14. Acab JC, Kvatum W, Ebo C. A 76 year old male with an unusual presentation of Merkel cell carcinoma. Int J Surg Case Rep 2016; 23: 177-181.

15. Feng $\mathrm{H}$, Shuda $\mathrm{M}$, Chang $\mathrm{Y}$ et al. Clonal integration of a polyomavirus in human Merkel cell carcinoma. Science 2008; 319: 1096-1100.

16. Miner AG, Patel RM, Wilson DA et al. Cytokeratin 20-negative Merkel cell carcinoma is infrequently associated with the Merkel cell polyomavirus. Mod Pathol 2015; 28: 498-504.

17. Spurgeon ME, Lambert PF. Merkel cell polyomavirus: a newly discovered human virus with oncogenic potential. Virology 2013; 435: 118-130.

18. Wendzicki JA, Moore PS, Chang Y. Large T and small T antigens of Merkel cell polyomavirus. Curr Opin Virol 2015; 11: 38-43.

19. Engels EA, Pfeiffer RM, Fraumeni JF Jr. et al. Spectrum of cancer risk among US solid organ transplant recipients. JAMA 2011; 306: 1891-1901.

20. Engels EA, Frisch M, Goedert JJ et al. Merkel cell carcinoma and HIV infection. Lancet 2002; 359: 497-498.

21. Wang TS, Byrne PJ, Jacobs LK et al. Merkel cell carcinoma. Semin Cutan Med Surg 2011; 30: 48-56.

22. Ma JE, Brewer JD. Merkel cell carcinoma in immunosuppressed patients. Cancers (Basel) 2014; 6: 1328-1350.

23. Tadmor T, Aviv A, Polliack A. Merkel cell carcinoma, chronic lymphocytic leukemia and other lymphoproliferative disorders: An old bond with possible new viral ties. Ann Oncol 2011: 22: 250-256.

24. Kaae J, Hansen AV, Biggar RJ et al. Merkel cell carcinoma: incidence, mortality, and risk of other cancers. J Nat/ Cancer Inst 2010; 102: 793-801.

25. Cusick L, Refsum SE. Merkel cell carcinoma of the breast: report of a case and review of the literature. Ulster Med J 2004; 73: 137-138.

26. Vladimirova LI, Nepomniashchaia EM, Kosinskaja TM. Synchronous Merkell cell skin cancer and breast cancer. Vopr Onkol 2010; 56: 465-468.

27. Mweempwa A, Tan A, Dray M. Recurrent Merkel cell carcinoma of the testis with unknown primary site: a case report. J Med Case Rep 2016; 10: 314.

28. Yaramada P, Lim BS, Flannery CM et al. Merkel cell carcinoma of unknown primary with lymph node andmesenteric metastasis involving the pancreas and duodenum. J Gastrointest Oncol 2016; 7 (Suppl 1): S66-S70.
29. Nguyen BD, McCullough AE. Isolated tibial metastasis from Merkel Cell carcinoma. Radiol Case Rep 2015; 2: 88.

30. AJCC (American Joint Committee on Cancer) cancer staging manual. $7^{\text {th }}$ ed. Edge SB, Byrd DR, Compton C (eds). New York et al.: Springer, 2010.

31. lacocca MV, Abernethy JL,Stefano CM et al. Mixed Merkel cell carcinoma and squamous cell carcinoma of the skin. J Am Acad Dermatol 1998; 39: 882-887.

32. Wong HH, Wang J. Merkel cell carcinoma. Arch Pathol Lab Med 2010; 134: 1711-1716.

33. Cheuk W, Kwan MY, Suster S et al. Immunostaining for thyroid transcription factor 1 and cytokeratin 20 aids the distinction of small cell carcinoma from Merkel cell carcinoma, but not pulmonary from extrapulmonary small cell carcinomas. Arch Pathol Lab Med 2001; 125: 228-231.

34. Hanly AJ, Elgart GW, Jorda $M$ et al. Analysis of thyroid transcription factor- 1 and cytokeratin 20 separates Merkel cell carcinoma from small cell carcinoma of lung. J Cutan Pathol 2000; 27: 118-120.

35. McNiff JM, Cowper SE, Lazova R et al. CD56 staining in Merkel cell carcinoma and natural killer-cell lymphoma: magic bullet, diagnostic pitfall, or both? J Cutan Pathol 2005; 32: 541-545.

36. Jaeger T, Ring J, Andres C. Histological, immuno-histological, and clinical features of Merkel cell carcinoma in correlation to Merkel cell polyomavirus status. J Skin Cancer 2012; 2012: 983421.

37. Koljonen V. Merkel cell carcinoma. World J Surg Oncol 2006; 4: 7.

38. Suárez AL, Louis $\mathrm{P}$, Kitts J et al. Clinical and dermoscopic features of combined cutaneous squamous cell carcinoma (SCC)/neuroendocrine [Merkel cell] carcinoma (MCC). J Am Acad Dermatol 2015; 73: 968-975.

39. Ramahi E, Choi J, Fuller CD et al. Merkel cell carcinoma. Am J Clin Oncol 2013; 36: 299-309.

40. Tai P. A practical update of surgical management of Merkel cell carcinoma of the skin. ISRN Surgery 2013; 2013: 850797.

41. Nghiem PT, Bhatia S, Lipson EJ et al. PD-1 blockade with pembrolizumab in advanced Merkel-cell carcinoma. N Engl J Med 2016; 374: 2542-2552.

42. Walocko FM, Scheier BY, Harms PW et al. Metastatic Merkel cell carcinoma response to nivolumab. J Immunother Cancer 2016; 4: 79. eCollection 2016. 